\title{
Intermediate Periodicities in Juniper Consumption and Sampling Strategies to Estimate the Diet of Free-Grazing Goats
}

\author{
J. W. Walker, ${ }^{1}$ D. F. Waldron, ${ }^{2}$ E. S. Campbell, ${ }^{3}$ C. A. Taylor, Jr., ${ }^{4}$ C. J. Lupton, ${ }^{2}$ and S. Landau ${ }^{5}$
}

Authors are ${ }^{1}$ Resident Director and ${ }^{2}$ Professor, Texas A\&M AgriLife Agricultural Research and Extension Center, San Angelo, TX 76901, USA; ${ }^{3}$ Postdoctoral Research Associate and ${ }^{4}$ Professor, Texas A\&M AgriLife Research Station, Sonora, TX 76950, USA; and ${ }^{5}$ Professor, Department of Natural Resources and Agronomy, Institute of Plant Science, Agricultural Research Organization, the Volcani Center, Bet Dagan, Israel 50250.

\begin{abstract}
We conducted this study to describe the intermediate-term periodicities in percentage juniper (Juniperus spp.) in goat diets and to develop optimal sampling schemes to estimate individual animal variation in juniper consumption. Fecal samples were collected from 12 multiparous female Angora goats on Monday and Thursday for a 24-mo period. Percentage juniper in the diet was determined using fecal near-infrared reflectance spectroscopy. Spectral analysis was used to determine the presence and length of cyclic variation in juniper consumption during growing and dormant season periods. Significant periodicities were found for $37 \%$ and $68 \%$ of the goats in the dormant and growing seasons, respectively. Cycle lengths varied from $9 \mathrm{~d}$ in the dormant season to 7 or $8 \mathrm{~d}$ in the growing season. The simple coefficient of determination between a two-sample moving average and the mean of all observations on individual goats was highest during a 3-mo period in the spring, which indicates that samples collected in the spring provided the best estimate of the yearlong percentage juniper in the diet. Monte Carlo simulations for 7-d cycles showed the root mean squared difference between estimated and population mean for two samples with 2 or $3 \mathrm{~d}$ between samples was only $1 \%$ greater than the root mean square difference for three or four samples collected every other day. The optimal sampling strategy for determining the dietary percentage of a species is to collect two samples separated by one-half of the cycle length.
\end{abstract}

Key Words: biological rhythms, diet selection, goat, juniper, periodogram, spectral analysis

\section{INTRODUCTION}

Animals demonstrate periodic variation in many behaviors (Sollberger 1965). The frequency of these cycles varies from short (seconds or less) to long (annual). Understanding these rhythms is of inherent interest for understanding foraging behavior as well as important for developing sampling schemes that ensure the behavior of interest is measured in a manner that provides an unbiased estimate of the parameter measured. Botanical composition of the diet of free-grazing herbivores has long been recognized to exhibit annual cycles (Fraps and Cory 1940), and more recently the existence of intermediate (Pfister et al. 1997) and short term (Parsons et al. 1994; Dziba and Provenza 2008) cycles in diet composition have been demonstrated. The ability to inexpensively measure the botanical composition of free-grazing herbivores using fecal near-infrared reflectance spectroscopy (F.NIRS; Walker et al. 2007) provides the opportunity to collect an adequate number of samples to investigate periodicities of diet selection in free-ranging herbivores.

Our immediate interest in the cyclic variation of diet selection is related to developing sampling protocols to accurately estimate the true propensity of goats to consume

\footnotetext{
The project was supported by Research Grant Award IS-3555-04 from BARD, The United States, Israel Binational Agricultural Research and Development Fund, and Texas Food and Fibers Commission Project b-04-05-02.

Correspondence: J. W. Walker, Texas A\&M AgriLife Agricultural Research and Extension Center, San Angelo, TX 76901, USA. Email: jwalker@ag.tamu.edu
}

Manuscript received 15 July 2012; manuscript accepted 27 November 2012.

(c) 2013 The Society for Range Management juniper (Juniperus spp.). Juniper contains monoterpenes (Owens et al. 1998; Campbell and Taylor 2007), and monoterpenes can regulate diet intake (Riddle et al. 1996; Dziba and Provenza 2008). A study using F.NIRS to estimate the heritability of percentage juniper in goat diets found that repeatability of juniper consumption was low (Waldron et al. 2009). Low repeatability could be caused by cyclic variation in the diet composition that was not adequately accounted for by the sampling scheme. If goats rhythmically vary the amount of juniper in their diets and this effect is not taken into account, it is possible to sample a goat at the apex of a cycle one time and the nadir the next. Such variation can greatly affect the outcome of studies where individual variation is the topic of interest such as in genetic studies.

The objectives of this study were to: 1 ) look for intermediate length periodicities; 2) determine the best season to collect samples to estimate an animal's true propensity for juniper consumption; and 3) use these results to determine an optimal sampling strategy for estimating the true percentage of juniper in a goat's diet.

\section{METHODS}

\section{Study Site, Animals, and Sampling}

The study was conducted at the Texas A\&M AgriLife Research Station at Sonora (lat $30^{\circ} 15^{\prime} \mathrm{N}$, long $\left.100^{\circ} 33^{\prime} \mathrm{W}\right)$, located in the western Edwards Plateau region of Texas. Long-term annual precipitation from 1918 through 2006 was $600 \mathrm{~mm}$ with a bimodal distribution consisting of spring and fall peaks. Soils are primarily the Tarrant series, which are in the thermic family 
of the Lithic Haplustolls (Thurow et al. 1988). Dominant are Tarrant stony clay soils, which are generally 15 to $30 \mathrm{~cm}$ deep. These soils contain $5 \%$ to $70 \%$ limestone fragments or limestone outcrops. The topography has gentle slopes of $3 \%$ to $4 \%$.

Taylor (2008) described the study site as characterized by scattered live oak (Quercus virginiana Mill.) mottes dominated by mature trees with encroaching Ashe (blueberry) juniper (Juniperus ashei Buchholz) and redberry (J. pinchotii Sudw.) juniper, both in the oak mottes and in the interspaces. The study pasture had about $45 \%$ woody plant cover, of which about $30 \%$ was Juniperus spp. There is little herbaceous vegetation under the woody plant canopy. Intercanopy vegetation is a mix of short and midgrasses, summer perennial forbs, and low palatability shrubs. Important midgrasses include sideoats grama (Bouteloua curtipendula [Michx] Toirr), Wright's threeawn (Aristida wrightii Nash), fall witchgrass (Digitaria cognata [Schult.] Pilg.), Texas wintergrass (Stipa leucotricha Trin. \& Rupr.), and cane bluestem (Bothriochloa barbinodis var. barbinodis Lag. Herter). Common short grasses are curly-mesquite (Hilaria belangeri [Steud.] Nash) and hairy grama (B. hirsute Lag.). Important forbs include Texas bluebonnet (Lupinus texensis Hook.), Upright prairie coneflower (Ratibida columnaris [Nutt.] Woot. \& Standl.), Texas croton (Croton texensis [Klotzsch] Müll. Arg.), Spreading sida (Sida abutifolia Mill.), Texas snoutbean (Rhynchosia texana Gillies ex Hook. var. texana [Torr. \& A. Gray] M.C. Johnst.), Plantago (Plantago spp.), Bushsunflower (Simsia spp.), Orange zexmenia (Wedelia texana [A. Gray] B.L. Turner), Oxalis (Oxalis spp.), Knotweed leafflower (Phyllanthus polygonoides Nutt. ex Spreng.), and Velvetleaf bundleflower (Desmanthus velutinus Scheele).

The same 16 ha pasture was used throughout this study. The stocking rate of 9.5 ha per animal unit equivalent is light moderate. Juniper availability far exceeded animal demand, and juniper intake was considered a function of availability and quality of alternative dietary choices.

Animals. Twelve multiparous female Angora goats, average age $3.7 \mathrm{yr}$ (range $=2$ to $7 \mathrm{yr}$ ) that weighed $31.5 \mathrm{~kg}(\mathrm{SD}=4.2 \mathrm{~kg})$ at the beginning of the study were used. The goats were selected from a flock of 279 does that had previously been measured to estimate juniper consumption. Based on three previous determinations of percentage juniper in their diets that were made between December 2003 and March 2004, half (six) of the goats were selected from the first quartile (goats with highest percentage juniper in their diet) and half were selected from the fourth quartile (goats with the lowest percentage juniper in their diet). Once selected, these does grazed the same 16-ha pasture for the next 24 mo beginning in September 2004, except for periods when they were moved to the drylot for a 21-d period in February 2005 and March 2006 for shearing and a subsequent period to allow regrowth of mohair in a protected environment prior to returning to pasture. Does were supplemented with approximately $0.11 \mathrm{~kg} \cdot \mathrm{d}^{-1}$ of whole cottonseed for $90 \mathrm{~d}$ both winters. Does were unbred throughout the study. All procedures involving animals were approved by the Texas A\&M University Institutional Agricultural Animal Care and Use Committee under protocol 2004215 .
Sampling Procedures. Fecal samples were collected to determine percentage juniper in the diet using near-infrared spectroscopy. When goats were on pasture, they were sampled twice weekly on Monday and Thursday except in February 2006 when they were sampled every other day for a total of 14 collections. To collect fecal samples does were penned in individual $46 \times 91 \mathrm{~cm}$ pens with expanded metal floors for about $1 \mathrm{~h}$ beginning at 0800 hours. Fecal samples, about $10 \mathrm{~g}$, were collected from screen bottomed trays located beneath the floor. A potential maximum of 196 samples were collected from each goat during the 24-mo study.

Sample Preparation and Analysis. Fecal samples were dried, ground in a cyclone mill to pass through a $1-\mathrm{mm}$ screen, dried in a forced-air oven $\left(50^{\circ} \mathrm{C}\right.$ for $\left.12 \mathrm{~h}\right)$, and conditioned for $24 \mathrm{~h}$ in an environment with constant temperature and humidity $\left(21^{\circ} \mathrm{C}, 65 \%\right.$ relative humidity). Approximately $4 \mathrm{~g}$ of ground and conditioned sample were packed into a quarter-cup sample cell with a near-infrared, transparent, quartz cover glass. Cells were scanned 32 times using a scanning reflectance monochromator (model 6500, NIR Systems Inc, Silver Spring, MD). Reflected energy $(\log [1 / R]$, where $R=$ reflectance) was measured and averaged over the 32 scans and recorded at $2 \mathrm{~nm}$ intervals from 1100 to $2500 \mathrm{~nm}$. Percentages of juniper in the diets were determined using previously established calibration equations (Walker et al. 2007, 2010). These calibrations have been successfully used and validated to accurately predict juniper consumption in environments that differed from the calibration environment (Utsumi et al. 2010).

\section{Statistical Analysis}

Analytical Periods. The data were divided into four sets of contiguous time series that represented two paired sets of time series that were paired for the same season and duration in different years (Fig. 1). A dormant season time series consisted of observations from October 2004 to January 2005 and a similar set for the 2005 to 2006 season; the two data sets are

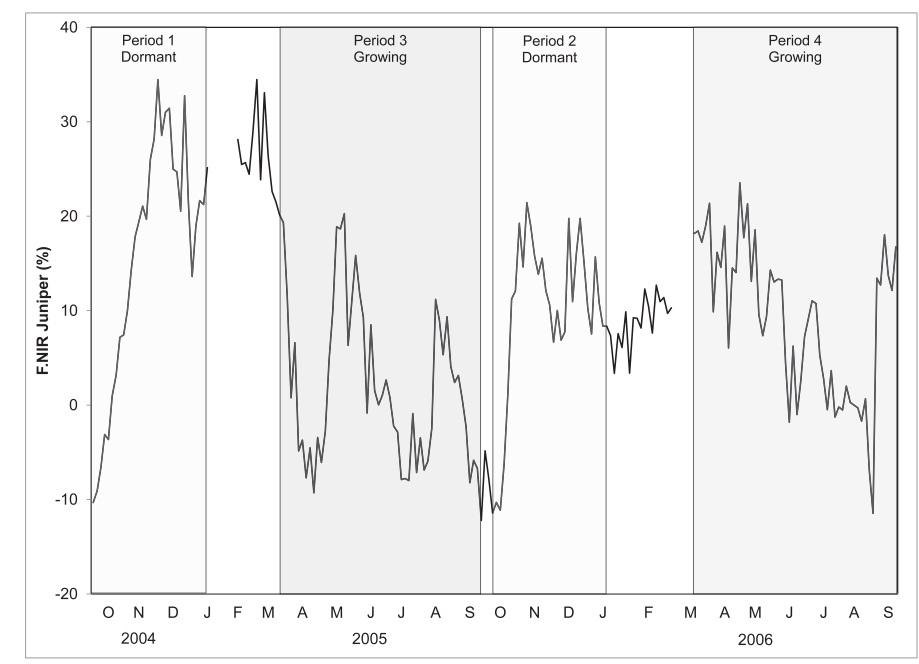

Figure 1. Average fecal near-infrared reflectance spectroscopy (F.NIRS) determined percentage juniper in the diet of 12 free-grazing female goats on a juniper woodland during a 2-yr period. Sample periods used for spectral analysis are shown. 
referred to as Period 1 and 2, respectively. There were 31 observations per animal in each of the Period 1 and 2 time series. A growing season time series consisted of observations from late March through mid September 2005 and a similar set for 2006; the two data sets are referred to as Period 3 and 4, respectively. There were 53 observations per animal in each of the Period 3 and 4 time series. In February 2006, a time series of 14 samples per animal collected every other day was analyzed to determine if a shorter sampling frequency changed the periodicity of detectable frequencies.

Spectral Analysis. Spectral analysis was used to determine if there was a regularly recurring cyclic pattern of percentage juniper in the diet of goats that could be used to specify an appropriate sampling interval. Assumptions for spectral analysis are that the data are a stationary time series of equally spaced observations with no missing observations. Because the data used in this study did not precisely meet these criteria, minor assumptions and interpolations were used to ensure the data were amenable to spectral analysis. The data used in this analysis were separated by repeating 3 - and 4-d intervals, and the interval between observations was assumed to be $3.5 \mathrm{~d}$. Missing observations (total of 54 observations or $2.3 \%$ of samples) that resulted from occasional missed collections on individual animals, and three missed collection days, were estimated using a least squares estimator that included the value of the observation before and after the missed observation and the 30-d moving average high temperature, which was an environmental variable that accounted for significant variation in percentage juniper in the diet. Because the data had seasonal trends, a first difference procedure was used to remove the seasonal trends (Diggle 1990). The first difference of a time series $\left\{y_{t}\right\}$, written $\left\{D y_{t}\right\}$ is defined by the transformation: $D y_{t}=y_{t}-y_{t-1}$. The periodogram is a description based on the superposition of sinusoidal waves of various frequencies on an observed time series. The value of this approach is the empirical observation that many time series exhibit cyclic fluctuation in value, but at frequencies which are not always predictable before the data are examined. The total variance of the time series is partitioned into sums of squares for the different cyclical components, i.e., different frequencies of the sine curves. These cyclical components were identified by Fourier frequencies $(\mathrm{w}=2 \pi / n)$ with a total of $n / 2$ frequencies, where $n$ is the number of observations in the time series. The total variance of the spectral data was partitioned into sums of squares also referred to as periodogram ordinates for the different cyclical components and large ordinate values indicated important frequencies. The SPECTRAL procedure of SAS (Brocklebank and Dickey 2003) was used to calculate the periodogram ordinate for all Fourier frequencies. The presence of significant periodicities was tested using the Kolmogorov-Smirnov test (Fuller 1996). $\chi^{2}$ analysis was used to test for the independence of cycle length for the largest periodogram ordinate between animals with significant and nonsignificant periodicities. Only animals with significant periodicities $(P<0.10)$ were used in subsequent analysis.

To increase precision for identifying the important frequencies, periodogram ordinates were averaged across animals with significant periodicities within each of the four periods and then smoothed with a two-point moving average (Diggle 1990). The yearly paired time series were tested for differences by comparing the ratio of the paired periodogram ordinates to the F-distribution with $2 r_{1}$ and $2 r_{2}$ degrees of freedom, where $r$ is the number of replicates in the periodogram ordinate (Diggle 1990).

Correlation Analysis. An empirical approach was used to determine the best time of year to sample goats to determine the percentage juniper in their diet. An animal's true propensity to consume juniper was defined as the mean of all observations on an individual animal for the 2-yr study $\left(\mathrm{JC}_{\mathrm{ALL}}\right)$. At each sample date, the percentage juniper in the diets of the 12 goats was used to calculate the simple coefficient of determination $\left(r^{2}\right)$ between a two-date moving average of percentage juniper in the diet of an individual goat at that date and $\mathrm{JC}_{\mathrm{ALL}}$ for the same animal. Thus, each $r^{2}$ consisted of 12 data pairs corresponding to the 12 goats in this study. Because the $r^{2}$ data were not independent and were not normally distributed $(P<0.005$, Shapiro-Wilk test $)$, a Wilcoxon signed rank test was used to test for differences between the mean $r^{2}$ for all observations and the individual $r^{2}$ calculated for the individual sample dates within a month. The Wilcoxon signed rank test was used to identify months that were better or worse than average for estimating $\mathrm{JC}_{\mathrm{ALL}}$. The $r^{2}$ values were tested to determine if they were correlated to the percentage juniper in the diets by pairing the $r^{2}$ with the two-date moving average percentage juniper in the diet for all goats at each time step.

Monte Carlo Simulations. Location and variance parameters of the original percentage juniper and the difference transformation were estimated using the MIXED procedure (SAS 2006). The model for this analysis included a fixed effect for period and random effects for animal and residual. Based on the periodicities detected in the spectral analysis, a Monte Carlo simulation to evaluate the effect of different sampling strategies was conducted. For the simulation, it was assumed that juniper consumption followed a sine curve with a specified period and assumed mean. A random deviate was added to represent residual variation. The amplitude of the sine curve was chosen to produce a variance similar to the observed within-animal variance. Simulated sampling points $(N=10000)$ were chosen on the sine wave to represent possible sampling protocols. The protocols included obtaining a single sample and multiple samples (two to four) with a specified number of days between samples. The difference between the mean of the samples and the actual juniper was calculated. The strategies were evaluated and ranked by the root mean squared difference.

\section{RESULTS}

Based on mean juniper consumption for the entire study, one goat from the first quartile of the initial selection was in the last quartile and one goat from the last quartile was in the first quartile of the goats used in this study. All other goats remained in their initial classification as high or low juniper consumers. The simple coefficient of determination for the prestudy and study estimates of juniper consumption was 0.18 . The mean difference between the two groups of goats for the prestudy period was 17 percentage units compared to 8 percentage units during the study, excluding the two goats that changed 
Table 1. Frequency of largest periodogram ordinance (i.e., the cycle length in days that accounted for greatest amount of variation) for juniper consumption for animals with significant (Sig., $P<0.10$ ) and nonsignificant (NS; $P \geq 0.10$ ) periodograms for each period.

\begin{tabular}{|c|c|c|c|c|c|c|c|c|c|c|}
\hline \multirow[b]{2}{*}{ Season } & \multirow[b]{2}{*}{ Period } & \multirow[b]{2}{*}{ Periodogram significance $(P<0.01)$} & \multicolumn{8}{|c|}{ Cycle length (d) } \\
\hline & & & 7 & 8 & 9 & 10 & 11 & 12 & 13 & $\geq 14$ \\
\hline \multirow[t]{4}{*}{ Dormant } & 1 & Sig. & 1 & 1 & 2 & 0 & 0 & 1 & 0 & 0 \\
\hline & & NS & 0 & 1 & 1 & 1 & 1 & 1 & 1 & 1 \\
\hline & 2 & Sig. & 1 & 2 & 1 & 0 & 0 & 0 & 0 & 0 \\
\hline & & NS & 3 & 0 & 1 & 1 & 1 & 0 & 1 & 1 \\
\hline \multirow[t]{4}{*}{ Growing } & 3 & Sig. & 1 & 4 & 1 & 1 & 0 & 0 & 0 & 0 \\
\hline & & NS & 1 & 2 & 0 & 0 & 0 & 0 & 0 & 2 \\
\hline & 4 & Sig. & 6 & 0 & 0 & 0 & 2 & 0 & 0 & 1 \\
\hline & & NS & 1 & 0 & 0 & 1 & 0 & 0 & 0 & 1 \\
\hline
\end{tabular}

quartiles. The mean juniper consumption from all 12 goats on the study for all sample days is shown in Figure 1. The negative values for juniper consumption are the result of the F.NIRS determinations of dietary botanical composition, which represent interval scale data, i.e., no true zero (Walker et al. 2007). Mean percentage juniper in the diets varied by about 40 percentage units during the study, and mean differences as large as 30 percentage units within a $7-d$ period were not uncommon. Periods of high and low juniper consumption were seen in both dormant and growing seasons, but on average juniper consumption was numerically higher in the dormant season.

The mean of all juniper observations from animals and periods that exhibited a significant periodicity was $7.8 \%$, and the mean absolute value of the difference $\left(\left\{D y_{t}\right\}\right)$ was 6.2 percentage units. The mean absolute value of the difference was 7.4, 5.8, 6.3, and 5.9 percentage units for Periods 1, 2, 3, and 4, respectively, which are estimates of the amplitude between adjacent observations.

Variance of the percentage juniper was 167.9 squared percentage units, and variance of the difference was 35.8 squared percentage units. Period was a significant $(P<0.001)$ source of variation for juniper, but not for the differences $(P>0.10)$. The variance component attributed to animal was 41.9 squared percentage units for juniper and only 0.6 for the difference. These results suggest that using the difference effectively removed among-period variation as well as among-animal variation.

\section{Periodicities of Juniper Consumption}

A test for the null hypothesis that the difference time series for individual animals represented white noise found significant $(P<0.10)$ periodicities for 5, 4, 7, and 9 of the 12 goats in Periods 1, 2, 3, and 4, respectively. Three of the goats had significant periodicities in all time periods, and three goats had no significant periodicities. The frequency of different period lengths for all animals is shown in Table 1. The fewer animals with significant periodicities in Periods 1 and 2 compared to Periods 3 and 4 may be the results of fewer time periods in the first two periods (31) compared to the latter periods (53). The frequency of animals with different cycle lengths indicated animals that had significant periodicities had more individuals with short cycle lengths in the dormant periods $(P=0.019$; i.e., Periods 1 and 2$)$ but not in the growing season $(P=0.371$; i.e.,
Periods 3 and 4). There was no difference $(P=0.55)$ in the number of goats with significant periodicities between the six highest juniper consuming goats (11 significant periodicities) and the six lowest juniper consuming goats (14 significant periodicities).

The average periodograms and spectral ratios for each period in Figure 2 include only goats with significant periodicities. The periodogram for the dormant season (Fig. 2a) showed similar patterns for both years, and the peak at $9 \mathrm{~d}$ indicates that the average cycle length was about $9 \mathrm{~d}$ (Fig. 2a). There were some differences between the periodograms for 2004 and 2005 (Fig. 2b), but these differences occurred after the peaks that represented the important cyclic patterns of variation. Furthermore, the differences between the spectra as indicated by the periodogram ordinates were primarily due to greater overall variation in 2004 compared to 2005 rather than differences in location of spectral peaks. The periodograms for the growing season (Fig. 2c) had a peak at 8 and $7 \mathrm{~d}$ for 2005
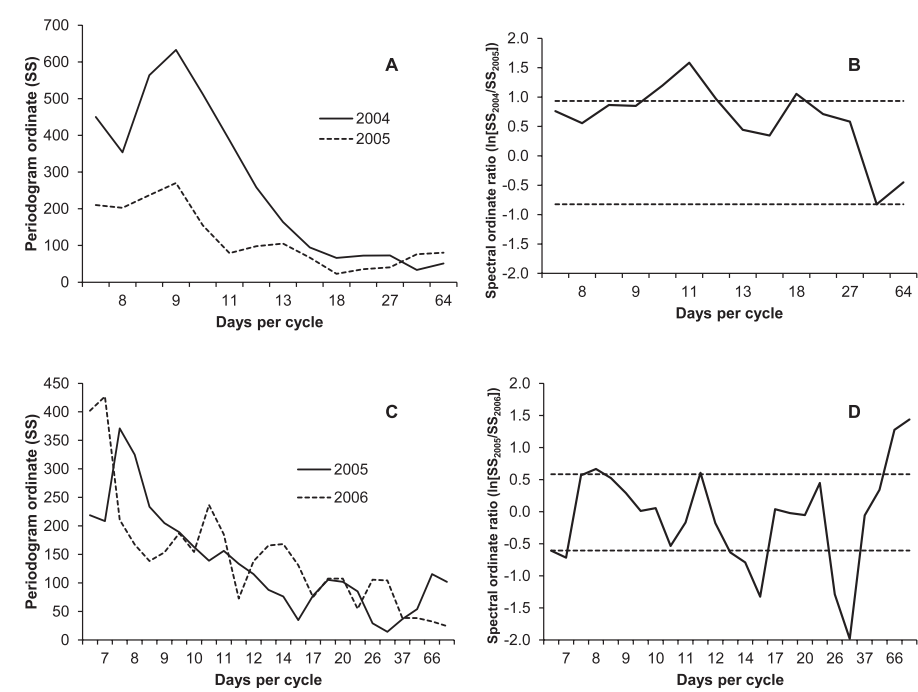

Figure 2. Periodogram ordinates, i.e., sums of squares (SS), in $A$ and $C$ and spectral ratios in $B$ and $D$ for first difference juniper consumption by goats on juniper woodlands for two different periods and years. Dormant season (October through January) periodogram and spectral ratio are shown in $A$ and $B$, respectively. Growing season (mid-March through midSeptember) periodogram and spectral ratio are shown in $C$ and $D$, respectively. Dashed lines (- - -) on B and D represent 95\% pointwise tolerance intervals assuming that the spectral ratios for the $2 \mathrm{yr}$ are equal. 
and 2006, respectively. Similar to the dormant season spectral ratios, differences between the growing season periodograms occurred after the peaks that represented important cyclic patterns (Fig. 2d). In February 2006, fecal samples were collected every other day for a total of 14 collections. Spectral analysis of these samples found no animals with significant $(P>0.13)$ cyclic patterns.

\section{Timing of Sampling}

The coefficients of determination between two-sample moving averages and the mean of all samples for an individual animal varied over time (Fig. 3). The $r^{2}$ was highest for a 3-mo period in the spring both years but began about 2 mo earlier in 2005 (March) than in 2006 (May). Coefficients of determination were lower in the fall and winter months as well as July and August of 2005. The correlation of the $r^{2}$ and the mean percentage juniper in the goat diets was positive but low $(r=0.169 ; P=0.011)$. Figure 3 indicates that the seasonal juniper consumption is most closely related to overall juniper consumption in the spring during the transition between high winter and low spring and summer consumption of juniper. The relationship between juniper consumption during a single month and overall juniper consumption declined once the animals were at the lower level of juniper consumption and when juniper consumption was increasing.

\section{Sampling Strategies}

A summary of the results of the sampling schedules is shown in Table 2. These values were calculated with the assumption that the cycle was $7 \mathrm{~d}$ long. The lowest root mean squared difference ( 2 percentage units) was obtained by taking either three or four samples, with $1 \mathrm{~d}$ between sample days. The value of the fourth sample in this scheme resulted in a slight

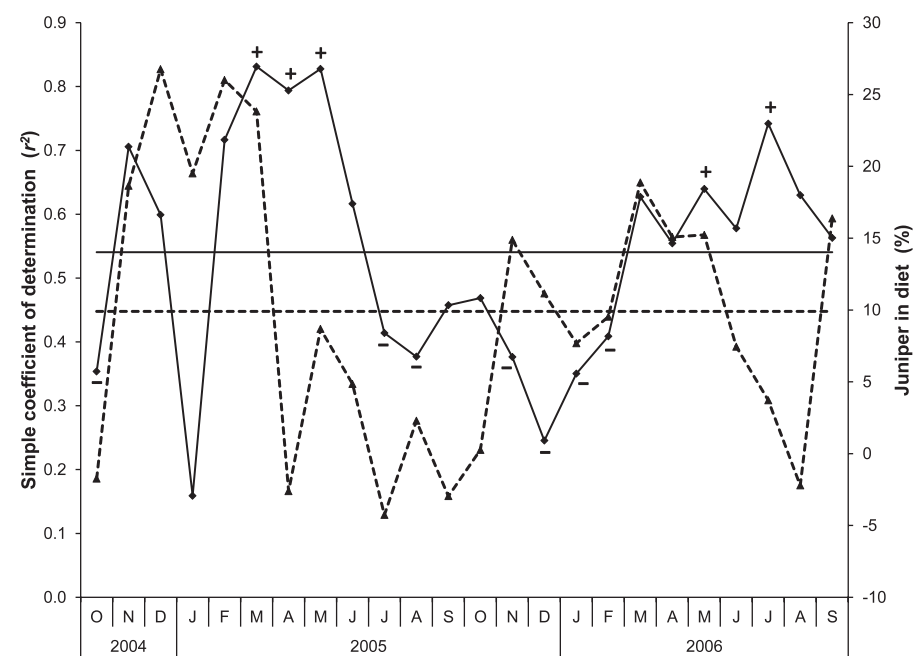

Figure 3. Solid line (-) is the average coefficient of determination $\left(r^{2}\right)$ for each month between the two-sample moving average value for individual goats and the mean for all of their observations. The solid horizontal line is the average $r^{2}$ for all moving averages, + indicates above-average months $(P<0.05)$, and - indicates below average months $(P<0.05)$. The dashed lines (- - -) are the monthly average percentage juniper in the diet, and the dashed horizontal line is the average percentage juniper in the diet for all months. improvement. Taking two or three samples, with $2 \mathrm{~d}$ between sampling days or two samples with $3 \mathrm{~d}$ between sampling days resulted in increased root mean squared difference of only 1 percentage unit. With an assumed uniform smooth cycle of $7 \mathrm{~d}$, obtaining a single sample, or two samples with 1 or $5 \mathrm{~d}$ between samples, or three or four samples on consecutive days will all result in root mean squared differences substantially greater than two samples with 2 or $3 \mathrm{~d}$ between sample days. The labor and expense involved to sample more than twice does not seem warranted for the small decrease in root mean squared difference.

The results in Table 2 are a function of the length of the cycle. The general conclusions are: 1) a single sample has limited value when the trait to be measured is cyclic; and 2) when multiple samples are possible, the number of days between samples is crucial and should be chosen so that subsequent samples are obtained near $\mathrm{P} / 2$ days later, where $\mathrm{P}$ is the length of the cycle in days.

\section{DISCUSSION}

Spectral analysis indicated that some goats consuming the chemically defended juniper plant demonstrated regularly occurring variation in composition of the diet with cycle lengths of 7 to $9 \mathrm{~d}$. Based on the results of the spectral analysis and an estimate of amplitude, the idealized cyclic variation for each period is shown in Figure 4. Variation from peak to trough during a 7 - to 9 -d cycle was about $50 \%$ of the range of the $95 \%$ confidence interval for mean juniper consumption across all observations. This indicates that intermediate length cycles are important sources of variation affecting animal diets and their impact on plant communities.

The assumed 3.5-d interval between samples limited the minimum detectable cycle length to $7 \mathrm{~d}$, which is referred to as the Nyquist frequency (Diggle 1990). The inability to detect cyclic patterns during February 2006 when sample intervals were $2 \mathrm{~d}$ may have been caused by the short length of the time series. However, inspection of the data did not indicate any cyclic patterns. This is not unexpected because spectral analysis of the dormant season time series in Periods 1 and 2 detected fewer animals showing cyclic variation in juniper consumption, which presumably is at least partly a result of limited dietary choices during the winter.

The actual variation in juniper consumption could have been greater than detected in this study. Whitworth (2002) found that when goats were fed a constant level of Juniper spp., 3 or 4 $\mathrm{d}$ were required for F.NIRS predictions to reflect changes of 10 and 30 percentage units, respectively. For the purpose of understanding the effect of such lag times on F.NIRS predictions on juniper in the diet, if it is assumed that goats varied their consumption of juniper uniformly over a 9-d cycle, the lag times shown by Whitworth (2002) would reduce the variation in juniper consumption found in this study by about half. Thus instead of the average difference of 12 to 14 percentage units between the peak and trough of a cycle using the methodology of this study, the actual difference could have been two times as great. However, because it is doubtful that juniper consumption varies uniformly as a sine curve, the actual variation was probably intermediate. This effect of lag time on 
Table 2. Comparison of sampling strategies based on Monte Carlo simulations using different numbers of samples and different intervals between samples and assuming cycle length is $7 \mathrm{~d}$. Results are the root mean squared differences (RMSD) between the population and simulated percentage juniper in the diet.

\begin{tabular}{lcccc}
\hline & \multicolumn{4}{c}{ Number of samples } \\
\cline { 2 - 5 } Days between samples & 1 & 2 & 3 & 4 \\
\hline & & \multicolumn{4}{c}{ RMSD \% Juniper } \\
0 & 11.0 & 10.0 & 8.0 & 6.0 \\
1 & - & 7.0 & 2.0 & 2.0 \\
2 & - & 3.0 & 3.0 & - \\
3 & - & 3.0 & - & - \\
4 & - & 7.0 & - & - \\
5 & - & 10.0 & - & - \\
\hline
\end{tabular}

estimating juniper in the diet would not affect estimates of cycle length.

Previous research on variation in diet selection and intake has tended to focus on either daily variations in pen feeding studies (Marsh et al. 2006; Dziba and Provenza 2008) or annual variations of free-grazing herbivores (Malechek and Leinweber 1972). However, in agreement with this study, Pfister et al. (1997) recognized the existence of intermediate length cycles and presented data on larkspur consumption of free-grazing cows that indicated that percentage larkspur in the diet varied over period lengths of 5 to $15 \mathrm{~d}$. Their work also indicated cycle lengths of about $5 \mathrm{~d}$ for animals in confinement feeding studies that used either larkspur or lithium chloride as aversive toxicants. Ellis et al. (2005) presented data that indicated juniper consumption in pen feeding studies varied over cycle lengths of 6 to $7 \mathrm{~d}$.

The 7-d and longer cycle lengths of percentage of chemically defended plants in the diets of free-grazing herbivores in this and other studies (Pfister et al. 1997) probably reflects a multitude of challenges faced by free-grazing herbivores. These challenges include foraging decisions at a variety of scales from landscape to bite (Senft et al. 1987), balancing variation in nutrient density with equal variation in plant secondary metabolites (PSM), and spatial variation in availability of different forage species. Similar to Duncan and Young (2002), who found that the ability of goats to differentiate among chemically defended plant species declined as the complexity of the learning environment increased, this study showed that the time step at which herbivores modulate their diet may reflect the way the question is asked, i.e., experimental protocol. Thus, although herbivores can regulate consumption of PSM on a daily basis, faced with the complexities of a rangeland environment, this study showed that they also have longer cycles.

Not all goats had a detectable cyclic pattern in juniper consumption, with an average of $38 \%$ and $67 \%$ of the goats demonstrating cyclic behavior in the dormant and growing seasons, respectively. Exhibition of a cyclic pattern was not related to a goat's propensity to consume juniper. Failure to detect significant periodicities in some animals did not mean they did not vary their diet but rather that the variation was not regular enough to correspond to at least one of the Fourier frequencies.

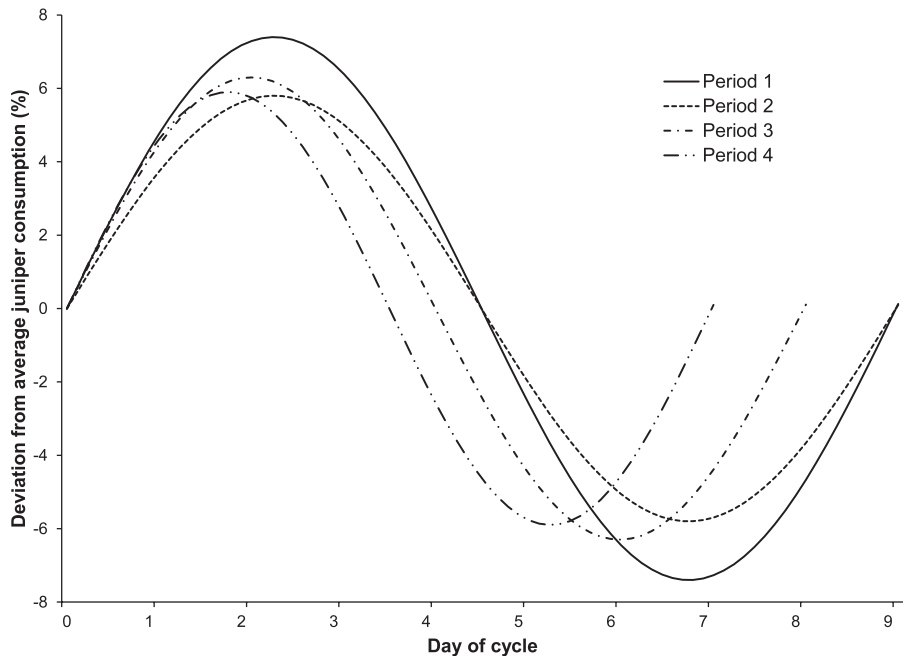

Figure 4. Idealized cyclic variation in juniper consumption by free-grazing goats that had significant $(P<0.10)$ periodograms. Sine curves are based on the major cycle length as determined by spectral analysis and the amplitude of the change between adjacent samples. Periods 1 and 2 were during the dormant season in 2004 and 2005, respectively. Periods 3 and 4 were during the growing season in 2005 and 2006, respectively.

With regards to seasonal timing of sampling, our initial hypothesis was that samples during the winter season when juniper consumption is greatest (Malechek and Leinweber 1972) would be more closely related to overall juniper consumption. This was not the case, and the relationship between percentage juniper in the diet for a given sample and overall juniper consumption was very weak. The higher correlation between percentage juniper in the diet in the spring (when juniper consumption was declining) and overall juniper consumption may simply reflect that during this time juniper consumption reflected the average of seasons when percentage juniper in the diet was high or low.

Monte Carlo analysis of different sampling designs clearly demonstrated that a single sample cannot be used to accurately estimate an individual animal's consumption of this chemically defended plant. If the number of days in the periodicity of the percentage of a plant in an animal's diet is known, the ideal sampling procedure is to collect two samples, where the time between samples is $\mathrm{P} / 2$ and where $\mathrm{P}$ is the number of days in a cycle.

The existence of periodicities in consumption of chemically protected plants may explain the higher differences in repeatability and heritability in studies that quantified the heritability of percentage mountain big sagebrush in sheep diets (Snowder et al. 2001) compared to the heritability of juniper in goat diets (Waldron et al. 2009). Intake of both of these plants is modulated by monoterpenes in the plant (Riddle et al. 1996; Dziba and Provenza 2007). The sheep study collected fecal samples twice each year with a 14-d interval between samples for $2 \mathrm{yr}$, and each sample was the composite of samples collected on 2 consecutive days. In contrast, the goat study collected samples once each year for $4 \mathrm{yr}$. The different sampling schemes could have resulted in greater residual error in the goat study and consequently a decrease in the estimates of heritability and repeatability for percentage of a chemically 
defended browse plant in the goat study as compared to the sheep study.

\section{IMPLICATIONS}

Consumption of juniper by free-grazing goats had a 7- to 9-d cycle. This indicates that regulation of PSM may occur over a longer time frame than typically has been studied. Sampling schemes must consider this variation to accurately estimate the percentage of a chemically defended plant in an herbivores diet, and the optimal sampling scheme in this case was determined to be two samples separated by one-half the cycle length. Proper sampling is particularly important when individual animal variation is important as in studies to estimate heritability of dietary preferences. The best season to collect samples to estimate yearlong consumption of juniper was in the spring, even though consumption was highest in the winter.

\section{ACKNOWLEDGMENTS}

The authors thank Sue Engdahl for performing F.NIR analysis and Nick Garza and Collin Rosser for help in collecting fecal samples.

\section{LITERATURE CITED}

Brocklebank, J. C., and D. A. Dickey. 2003. SAS for forecasting time series. 2nd ed. Cary, NC, USA: SAS Institute, Inc. 424 p.

Campbell, E. S., and C. A. Taylor, JR. 2007. Monoterpene production in redberry juniper foliage following fire. Rangeland Ecology \& Management 60:104-109.

DigGLE, P. 1990. Time series: a biostatistical introduction. Oxford, UK: Oxford University Press. $272 \mathrm{p}$.

Duncan, A. J., AND S. A. Young. 2002. Can goats learn about foods through conditioned food aversions and preferences when multiple food options are simultaneously available? Journal of Animal Science 80:2091-2098.

DziBA, L. E., and F. D. Provenza. 2008. Dietary monoterpene concentrations influence feeding patterns of lambs. Applied Animal Behavior Science 109:49-57.

Ellis, C. R., R. E. Jones, C. B. Scott, C. A. Taylor, J. W. Walker, and D. F. Waldron. 2005. Sire influence on juniper consumption by goats. Rangeland Ecology \& Management 58:324-328.

FraPs, G. S., AND V. L. CoRy. 1940. Composition and utilization of range vegetation of Sutton and Edwards Counties. College Station, TX, USA: Texas Agricultural Experiment Station. Bulletin 586. $39 \mathrm{p}$.

Fuller, W. A. 1996. Introduction to statistical time series. 2nd ed. New York, NY, USA: Wiley Press. 728 p.

MaleCheK, J. C., AND C. L. Leinweber. 1972. Forage selectivity by goats on lightly and heavily grazed ranges. Journal of Range Management 25:105-111.
Marsh, K. J., I. R. Wallis, R. L. Andrew, and W. J. Foley. 2006. The detoxification limitation hypothesis: where did it come from and where is it going? Journal of Chemical Ecology 32:1247-1266.

Owens, M. K., C. D. Lin, C. A. TAYLOR, And S. G. Whisenant. 1998. Seasonal patterns of plant flammability and monoterpenoid content in Juniperus ashei. Journal of Chemical Ecology 24:2115-2129.

Parsons, A. J., J. A. Newman, P. D. Penning, A. Harvey, and R. J. Orr. 1994. Diet preference of sheep: effects of recent diet, physiological state and species abundance. Journal of Animal Ecology 63:465-478.

Pfister, J. A., F. D. Provenza, G. D. Manners, D. R. Gardner, and M. H. Ralphs. 1997. Tall larkspur ingestion: can cattle regulate intake below toxic levels? Journal of Chemical Ecology 23:759-777.

Riddle, R. R., C. A. Taylor, M. M. Kothmann, and J. E. Huston. 1996. Volatile oil contents of ashe and redberry juniper and its relationship to preference by Angora and Spanish goats. Journal of Range Management 49:35-41.

SAS. 2006. SAS online doc 9.1.3. Cary, NC, USA: SAS Institute, Inc. Available at: http://support.sas.com/onlinedoc/913/docMainpage.jsp. Accessed 1 September 2011.

Senft, R. L., M. B. Coughenour, D. W. Balley, L. R. Rittenhouse, O. E. Sala, and D. M. Swif. 1987. Large herbivore foraging and ecological hierarchies. Bioscience 37:789-799.

Snowder, G. D., J. W. Walker, K. L. Launchbaugh, and L. D. Van Vleck. 2001. Genetic and phenotypic parameters for dietary selection of Mountain Big Sagebrush (Artemisia tridentata ssp. Vaseyana [Rydb] Beetle) in Rambouillet sheep. Journal of Animal Science 79:486-492.

Sollberger, A. 1965. Biological rhythm research. New York, NY, USA: Elsevier Publishing Company. $461 \mathrm{p}$.

TAYLOR, C. A., JR. 2008. Ecological consequences of using prescribed fire and herbivory to manage Juniperus encroachment. In: 0. W. Van Auken [ED.]. Western North American Juniperus communities. New York, NY, USA: Springer. p. 239-252.

Thurow, T. L., W. H. BlackBurn, and C. A. Taylor. 1988. Infiltration and interrill erosion responses to selected livestock grazing strategies, Edwards-Plateau, Texas. Journal of Range Management 41:296-302.

Utsumi, S. A., A. F. Cibls, R. E. Estell, T. T. Baker, and J. W. Walker. 2010. One-seed juniper sapling use by goats in relation to stocking density and mixed grazing with sheep. Rangeland Ecology \& Management 63:373-386.

Waldron, D. F., C. A. Taylor, JR., J. W. Walker, E. S. Campbell, C. J. Lupton, T. D. Willingham, and S. Y. Landau. 2009. Heritability of juniper consumption in goats. Journal of Animal Science 87:491-495.

Walker, J. W., E. J. Campbell, R. W. Kott, S. Y. Landau, C. J. Lupton, C. B. Scott, L. Surber, C. A. TAYloR, JR., and W. R. Whitworth. 2010. Fecal NIRS for predicting botanical composition of herbivore diets. In: J. Walker and D. Tolleson [EDS.]. Shining light on manure improves livestock and land management. San Angelo, TX, USA: Texas AgriLife Research. Technical Bulletin SANG-2010-0250. p. 5365.

Walker, J. W., E. S. Campbell, C. J. Lupton, C. A. Taylor, JR., D. F. Waldron, and S. Y. LANDAU. 2007. Effects of breed, sex, and age on the variation and ability of fecal near-infrared reflectance spectra to predict the composition of goat diets. Journal of Animal Science 85:518-526.

WHITWORTH, W. R. 2002. Estimating redberry and ashe juniper intake using fecal NIRS [MS thesis]. San Angelo, TX, USA: Angelo State University. 46 p. 